See Article page 92.

\section{Commentary: Leaflet perforation after transcatheter aortic valve replacement: An unsuspected complication with underestimated outcomes}

\author{
Samantha Guimaron, MD, MSc, \\ Dimitri Kalavrouziotis, MD, FRCSC, and \\ Siamak Mohammadi, MD, FRCSC
}

The indications for transcatheter aortic valve replacement (TAVR) have recently been widened to low-surgical risk patients. ${ }^{1}$ As surgical risk decreases, so does the average age of the patients. One major consideration remains: TAVR prosthesis durability, which has been poorly investigated thus far. Several authors have suggested that different mechanisms, all involving some extent of leaflet damage, including cusp rupture, leaflet thrombosis, and accelerated calcification, could have major consequences on valve durability and therefore on patient outcomes after TAVR. ${ }^{2,3}$ These lesions appear to be responsible for aortic regurgitation and the need for surgical explant. ${ }^{4}$ However, these lesions remain underdiagnosed.

In this issue of the Journal, Liesman and Fukuhara ${ }^{5}$ report 2 cases of leaflet perforation with a need for surgical explant. These cases share several common aspects: first, both patients had a history of chest radiation therapy with severe root calcification; second, both cases received a TAVR procedure with a self-expandable valve after a primary sternotomy; and third, surgical explant because of aortic regurgitation was required in both cases after a short

\footnotetext{
From the Division of Cardiac Surgery, Quebec Heart and Lung Institute, Laval University, Quebec City, Quebec, Canada.

Disclosures: The authors reported no conflicts of interest.

The Journal policy requires editors and reviewers to disclose conflicts of interest and to decline handling or reviewing manuscripts for which they may have a conflict of interest. The editors and reviewers of this article have no conflicts of interest.

Received for publication April 19, 2020; revisions received April 19, 2020; accepted for publication April 22, 2020; available ahead of print May 1, 2020.

Address for reprints: Siamak Mohammadi, MD, FRCSC, Department of Cardiac Surgery, Quebec Heart and Lung Institute, 2725 Chemin Sainte-Foy, Quebec City, Quebec, Canada, G1V 4G5 (E-mail: siamak.mohammadi@fmed.ulaval.ca). JTCVS Techniques 2020;3:95-6

2666-2507

Copyright (C) 2020 The Authors. Published by Elsevier Inc. on behalf of The American Association for Thoracic Surgery. This is an open access article under the CC BY-NCND license (http://creativecommons.org/licenses/by-nc-nd/4.0/).

https://doi.org/10.1016/j.xjtc.2020.04.014
}

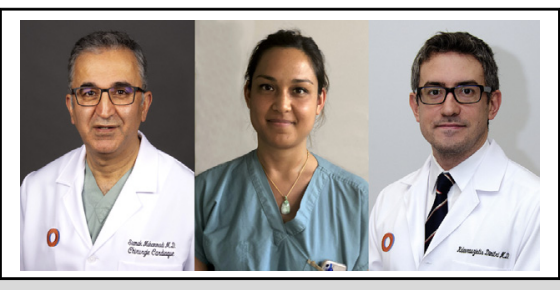

Siamak Mohammadi, MD, FRCSC, Samantha Guimaron, MD, MSc, and Dimitri Kalavrouziotis, MD, FRCSC

\section{CENTRAL MESSAGE \\ Leaflet perforation after trans- catheter aortic valve implanta- tion is a rare complication that may alter valve durability due to transcatheter valve leaflet vulnerability.}

period following the TAVR procedure: 3 and 5.8 years. Similar macroscopic findings were also noted: neo-endothelialization of the TAVR prosthesis nitinol frame into the aortic wall, with a perforation/tear located on the right coronary cusp.

Liesman and Fukuhara ${ }^{5}$ unmask a major unknown of TAVR prostheses: valve durability/longevity. The 2 cases occurred in the early- to mid-term follow-up post-TAVR, which suggests that leaflet fragility could have a negative impact on valve durability. Hypothetic risk factors for leaflet perforation were additional postdeployment balloon dilatation, as well as crimping of the prosthesis, which has also been reported by others. ${ }^{2}$ In addition, they suggested that valve durability could be further affected by implanting the prosthesis into an undecalcified native aortic valve and aortic root. This article is important because the authors effectively shed some light into a potential mechanical failure of TAVR due to the leaflet injury. The newer generation of TAVR bioprostheses has leaflets that are generally thinner to accommodate the smaller caliber of the delivery sheaths, which may translate into a potentially increased fragility of the leaflets. Further mechanical stress may be due to the crimping process, recapturing, and postdeployment balloon dilatation, and may render the leaflets vulnerable to perforation and subsequent thrombosis, although these theories remain hypothetical. Further studies are needed to assess these issues.

Liesmann and Fukuhara ${ }^{5}$ have exposed a novel but potentially underdiagnosed complication of TAVR prosthetic leaflet perforation. The durability of TAVR 
prostheses should be considered in our decisional algorithm when assessing the optimal approach to aortic stenosis, especially in younger patients.

\section{References}

1. Mack MJ, Leon MB, Thourani VH, Makkar R, Kodali SK, Russo M, et al; PARTNER 3 Investigators. Transcatheter aortic-valve replacement with a balloonexpandable valve in low-risk patients. $N$ Engl J Med. 2019;380:1695-705.
2. Alavi SH, Groves EM, Kheradvar A. The effects of transcatheter valve crimping on pericardial leaflets. Ann Thorac Surg. 2014;97:1260-6.

3. Park H, Wai Sang SL, Merhi WM. Extremely early structural failure of a self-expanding transcatheter aortic valve secondary to leaflet dehiscence. J Thorac Cardiovasc Surg Tech. March 19, 2020 [Epub ahead of print].

4. Fukuhara S, Brescia AA, Shiomi S, Rosati CM, Yang B, Kim KM, et al. Surgical explantation of transcatheter aortic bioprostheses: results and clinical implications. J Thorac Cardiovasc Surg. January 12, 2020 [Epub ahead of print].

5. Liesman DR, Fukuhara S. Leaflet perforation or tear late after transcatheter aortic valve implantation. J Thorac Cardiovasc Surg Tech. 2020;3:92-4. 